\section{0-210 OBSTETRICAL COMPLICATIONS ASSOCIATED WITH PRETERM DELIVERY AND INTRAVENTRICULAR HAEMORRHAGE IN PRETERM INFANTS: RESULTS FROM THE FRENCH NATIONAL COHORT EPIPAGE 2}

${ }^{1} \mathrm{M}$ Chevallier, ${ }^{2} \mathrm{~T}$ Debillon, ${ }^{1} \mathrm{~V}$ Pierrat, ${ }^{3} \mathrm{~S}$ Marret, ${ }^{1} \mathrm{PY}$ Ancel. ${ }^{1}$ Research Unit on Perinatal Health and Women's Health, INSERM U953, Paris, France; ${ }^{2}$ Neonatal Intensive Care Unit, Grenoble University Hospital, Grenoble, France; ${ }^{3}$ Neonatal Intensive Care Unit, Rouen University Hospital, Rouen, France

\subsection{6/archdischild-2014-307384.280}

Backgrouds and aim Despite the improvement in neonatal care, intraventricular haemorrhage (IVH) remains an important cause of neurodevelopmental anomalies in preterm infants (PI). This event is usually associated with gestational age (GA). Others factors like maternal complications associated with preterm delivery could be implicated. We studied the association between these maternal complications and IVH in a large cohort of PI.

Methods The data were extracted from the national Epipage 2 study, which included PI born before 32 weeks gestation during the year $2011(\mathrm{n}=3492)$. Neonatal and Obstetrical data were collected from the medical records including the postnatal cerebral ultrasound results. We used a polytomic logistic regression to compare the risk of the different grades of IVH according to the usual obstetrical complications associated with preterm birth. Results The incidence of grade $1 \mathrm{IVH}$ was $16.7 \%$ [95\% CI: 15.2-17.7], grade 2 was 10.5\% [95\% CI: 9.6-11.6], grade 3 was $5.6 \%$ [95\% CI: $4.8-6.3$ ] and grade $4: 3.7 \%$ [95\% CI: $3.1-$ $4.3 \%]$. Infants born when preterm labour with inflammatory syndrome was present had significantly more grade 3 and IV IVH than those exposed to maternal vascular disease (respectively $12.6 \%$ and $7.3 \%$ vs $1.8 \%$ and $3.4 \%$ ). After adjustment for GA and others confounding factors, grade $4 \mathrm{IVH}$ was strongly associated with preterm labour with inflammation (OR: 1.56 [95\% CI: 1.3-18.5]) and placental abruption (OR: 2.3 [95\% CI: 1.7-38.0]). Grade 3 IVH was only associated with placental abruption (OR: 4.6 [95\% CI: 1.3-16.8]).

Discussion This study demonstrates that IVH is associated with other factors independent of GA, as well as certain maternal complications. These results are useful for the management of preterm birth and help better understand the mechanisms of IVH.

\section{0-211 LARNYGOSCOPE BURNS IN NEONATAL INTUBATION}

${ }^{1}$ E Ryan, ${ }^{2} \mathrm{PO}$ Neill, ${ }^{2} \mathrm{D}$ Brabazon, ${ }^{1} \mathrm{JFA}$ Murphy. ${ }^{1}$ Neonatology, National Maternity Hospital, Dublin, Ireland; ${ }^{2}$ School of Mechanical and Manufacturing Engineering, Dublin City University, Dublin, Ireland

10.1136/archdischild-2014-307384.281

Introduction There is a paucity of information about the light and heat output of laryngoscopy equipment. We became concerned about the potential of a laryngoscope blade burn following an episode during intubation We mounted an in-vitro study of larynoscopes to determine the temperatures reached during clinical use.

Methods The temperature of the incandescent light bulb from ten different laryngoscopes was measured using a Real Time controller from National Instruments for data logging into a PC.

A second set of tests were performed using two fibre optic laryngoscope head designs. The temperature was measured every half a second for ten minute duration from the point in time at which the light was turned on in all devices. The temperature fall times from closing and simultaneous turning off of the laryngoscope light were also recorded.
Results Peak temperature was found to be consistently above 50 ${ }^{\circ} \mathrm{C}$ in four different brands of light bulb protruding laryngoscope heads. On closing the laryngoscope temperatures were all below $30^{\circ}$ at a one minute interval. In comparison, the fibre optic laryngoscope heads did not reach temperatures higher than $27.5^{\circ} \mathrm{C}$. Discussion The findings from our study indicate that within 30 seconds all ten laryngoscopes, with light-bulb sources, had gained significant heat to cause thermal injury to neonatal skin. LED laryngoscopes did not.

Conclusions We recommend that the laryngoscope blade is not left open prior to intubation and that it is closed between intubation attempts.

\section{0-212 NON-INVASIVE ESTIMATION OF THE PACO2 WITH VOLUMETRIC CAPNOGRAPHY IN CHILDREN MECHANICALLY VENTILATED}

F Baudin, P Bourgoin, D Brossier, S Essouri, G Emeriaud, M Wysoki, P Jouvet. Paediatric

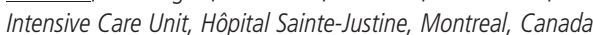

\subsection{6/archdischild-2014-307384.282}

Background In paediatric intensive care unit (PICU), the relationship between end-tidal partial pressure of carbon dioxide $\left(\mathrm{PetCO}_{2}\right)$ and arterial partial pressure of carbon dioxide $\left(\mathrm{PaCO}_{2}\right)$ may vary dramatically ( $\mathrm{PetCO}_{2}-\mathrm{PaCO}_{2}$ difference between -36 and $63 \mathrm{mmHg}$ ) (1). The aim of our study was to develop a model using volumetric capnography (VolCap) to better predict $\mathrm{PaCO}_{2}$ in mechanically ventilated children.

Material and methods We conducted a prospective clinical study that included all children admitted at Ste-Justine hospital, age 3 $\mathrm{kg}$, mechanically ventilated $>12 \mathrm{~h}$, with an arterial cannula. After literature review, we collected specific data from medical record including demographic data, clinical informations, ventilation, VolCap (NM3, Respironics, Philips, USA) and biological parameters. VoCap was recorded $15 \mathrm{~min}$ before an arterial blood gas and analysed breath-by-breath using a specific software (FlowTool, Philips, USA). The predictive model for $\mathrm{PaCO}_{2}$ was developed using a linear multivariable regression with the best determination coefficient (R2).

Results 43 children (26 boys, 60\%) age of 52 [9-137] months were included. Children with Tidal volume less than $30 \mathrm{ml}$ were excluded because of technical bias in VolCap interpretation by the software. In linear multivariable regression, the best model included the mean airway pressure $(\mathrm{p}=0.01), \operatorname{PetCO}_{2}\left(\mathrm{p}_{2}(\mathrm{p}=\right.$ $0.014)$ and the capnographic index (100*Slope SIII/Slope SII) (p $=0.003$ ) with a $\mathrm{R}^{2}=0.85$.

Conclusion Our preliminary results show that VoCap can help to improve the non-invasive estimation of $\mathrm{PaCO}_{2}$. Further research is necessary to validate the accuracy of our model.

\section{REFERENCE}

1 McDonald et al. Pediatr Crit Care Med 2002;3:244-249

\section{0-213 ASSOCIATION OF E-NOS GENE POLYMORPHISM IN DEVELOPMENT OF BRONCHOPULMONARY DYSPLASIA}

${ }^{1} \mathrm{M}$ Cetinkaya, ${ }^{2} \mathrm{I}$ Varturk, ${ }^{2} \mathrm{M}$ Korachi, ${ }^{3} \mathrm{~S}$ Guven, ${ }^{4} \mathrm{IM}$ Akin, ${ }^{1} \mathrm{~T}$ Erener-Ercan, ${ }^{1} \mathrm{G}$ Buyukkale. ${ }^{1}$ Neonatology, Kanuni Sultan Suleyman Training and Research Hospital, Istanbul, Turkey, ${ }^{2}$ Department of Genetics and Bioengineering, Yeditepe University Faculty of Engineering and Architecture, Istanbul, Turkey; ${ }^{3}$ Pediatrics, Umraniye Training and Research Hospital, Istanbul, Turkey; ${ }^{4}$ Neonatology, Medeniyet University Goztepe Training and Research Hospital, Istanbul, Turkey

10.1136/archdischild-2014-307384.283 